follows that a gene which is now a polygene acting at a late stage in the development of an organ may, either alone or as part of a complex of linked polygenes, assume the role of a switch gene if and when the developmental history of that organ is extended by its morphological and functional elaboration. A gene which has a minor effect on the corolla structure of a relatively unspecialized flower could have a drastic effect on the corolla of a flower elaborated and specialized in the way observed, for example, in an orchid.

This is, perhaps, an unduly simplified discussion of the problem, and the questions raised, for example, by neoteny require consideration at a length not now possible. But the principle that genes have evolved in function can scarcely be denied. Indeed the evolution of an organism is an expression of the functional evolution of its genes.

'Bateson, W., “Mendel's Principles of Heredity", University Press, Cambridge (1909).

Bridges, C. B., Amer. Nat., 56, 51 (1922).

- Fisher, R. A., Trans. Ent. Soc., 75, 269 (1927).

- Muller, H. J., Proc. 6th Int. Congr. Genetics, 1, 213 (1932).

'Timoféeff-Ressovsky, N. W., Nachr: Ges. Wiss. Göttingen (Biol.) (N.F.), 1, 53 (1934).

'Ford, E. B., Biol. Rev., 12, 461 (1937).

'Muller, H. J., “The New Systematics"' (p. 185). Clarendon Press, Oxford (1940).

"Huxley, J. S., "Evolution", Allen and Unwin, London (1942).

- Waddington, C. H., NATURE, 150, 563 (1942).

10 Mather, K., Biol. Rev. (in the Press).

"Haskell, G. M. L. (in preparation for publication).

"Mather, K., J. Genet., 41, 159 (1941).

${ }^{1 s}$ Mather, K., and de Winton, D., Ann. Bot. N.S., 5, 297 (1941).

"Mather, K. (unpublished).

${ }^{15}$ Brieger, F., "Selbststerilität und Kreuzungssterilităt", Springer, Berlin (1930).

\section{STUDIES OF WILD POPULATIONS}

\section{By Dr. C. B. WILLIAMS}

$\Lambda \mathrm{T}$ a joint meeting of the Royal Entomological Society and the Genetical Society held on December 3, there was a general discussion on methods of study of wild populations.

Prof. R. A. Fisher, president of the Genetical Society, opened the proceedings with an account of recent developments in the method of estimating the numbers of a wild population by liberating a known number of marked individuals and later recapturing a random sample. Thus if a hundred marked flies are liberated and, after a short interval to allow of their mixing with the wild population, a number of flies are captured at random and found to include 1 per cent of marked individuals, then it can be assumed that the original wild population was approximately ninety-nine times the number of marked flies or 9,900 individuals.

If a series of such observations are made at short intervals; say on successive days or every week, it is possible to extend the mathematical analysis to supply estimates, on one hand of the death and emigration rates, and on the other hand the birth or immigration rates. If several contiguous areas are sampled the effect of birth and death can be separated from the effects of movement.

Since the total number of individuals captured and the total released on different days may vary, it is of value to convert all to a 'recapture frequency' which is the number of marked recaptures to be expected if both the numbers released and the total number recaptured were a hundred.

The method has been used particularly with tsetse flies by Jackson in East Africa and on certain butterflies and moths in England particularly by Ford, and there are interesting differences between the former case, in which the insects are flying over long periods with relatively small changes of number, and the latter, in which the brood rises to a peak and falls away again within a few weeks.

The idea of random sampling, which is the central and typical statistical operation, aims at supplying estimates of the population numbers, and birth-rate and death-rate, together with a knowledge of the precision of these estimates which is seldom available by other methods.

Dr. C. B. Williams dealt with some methods of finding the changes in insect population used at Rothamsted Experimental Station in recent years. Direct sampling had been used by Dr. H. F. Barnes to trace the changes in numbers of wheat midges over a period of fourteen years, and the number of slugs caught in thirty minutes at night had been found to be a fairly accurate method for estimating changes in a slug population. Direct sample counts had been used by K. D. Baweja to demonstrate the return of the insect population to an area of soil previously rendered sterile by heat.

The method of sampling by means of a light trap provided an interesting mathematical problem, as the catch in the trap is directly affected by changes both in activity and in population numbers. By considering the difference between catches at short intervals (for example, successive days) the activity factor became dominant, while by comparing monthly average captures in successive years the population effect was emphasized. It was then found possible to correct average catches for the effect of environment on activity and to have left a more exact measure of the population change. Later it was found possible to forecast these changes from a knowledge of the weather conditions during the previous months.

Dr. Williams also dealt very briefly with a new method, recently developed by Prof. R. A. Fisher and himself, for studying the relative abundance of different species in a mixed wild population. By means of a logarithmic series it is possible, if one knows the number of individuals and the number of species in a random sample of a mixed population, to calculate three sets of information. First the relative frequency of rarer and commoner species, as for example the number of species represented in the sample by one, two, three or more individuals; secondly, the number of species which would have been obtained in samples containing fewer or more individuals from the same population; and thirdly, a numerical measure of the extent to which the population is divided up among species, which has provisionally been called the 'index of diversity'. As the error of this 'index' can also be calculated it is possible to say if two random samples are taken from populations of similar composition or not. The calculated results fit very closely indeed to the observed numbers.

Mr. George Salt pointed out that there are two principal aspects to the study of animal populations. One can ask the question "How many ?" and answer it by making a census; or one can ask "How do there come to be so many, neither more nor fewer ?" The curve of population growth, stated by Malthus on theoretical grounds to be exponential, was found by Pearl, Gauss and others in a variety of experiments to begin as though exponential, but then to change over to a sigmoid form. Three groups of 
factors have been suggested as effecting the change : competition for food, conditioning of the medium, and density of population. Owing to its applicability to human populations, the last of these has monopolized the interest of most observers; the second has been the subject of much work by Park; the first, competition for food, has been comparatively neglected. Experiments with blowflies show that, as increasing numbers of maggots compete for a fixed amount of meat, the average weight of the surviving larvæ gradually falls, there is an increasing loss of life in the larval stage, and eventually the number of survivors falls off rapidly. These laboratory experiments have their parallel in wild populations, and Holdaway has shown that, from an initial population of 63,200 Lucilia larvæ competing for carrion in Nature, only thirty reached the adult stage. A similar illustration of the law of diminishing returns has been demonstrated in a parasitic insect. In the case of these animals, and probably of others, it is in the larval stage, the principal feeding period, that the size of the population is largely determined by the available food supply.

Owing to the absence of Dr. Julian Huxley, who was to have taken part in the discussion, a communication was read from Dr. Ll. Lloyd on the effect of environment and competition for food on the insect fauna of sewage beds.

The population studied was made up of relatively few species, including three Chironomids, two Psychodids and one Enchytraeid worm, and it was possible in this simple community to see the effects of both intra- and inter-specific competition for food.

The vigorous Chironomid, Metriocnemus longitarsus, and the worm Lumbricillus lineatus dominate the situation and live in the topmost zone in the beds where the eggs of most species are laid. Cool wet summers are favourable to these dominant competitors, while hot dry summers are adverse to them. A cool June is followed by an abundance of $M$. longitarsus and a consequent reduction of the other Chironomids, $M$. hirticollis and Spaniotoma minima. The latter, however, specially counters the Psychodids deeper in the beds, so that these have a more prolonged abundance after a cool June.

$M$. longitarsus and Psychoda severina have the capacity of active winter breeding and one would expect that mild winters would be favourable to them. But the worm intervenes, and in a mild winter pulverizes the surface growth and sooner or later destroys it. Thus conditions are made more unsuitable for the two insects and they tend to become scarcer rather than more abundant in mild winters.

A. N. Barker, in a parallel study of the Protozoa of the beds, found a close negative correlation between the abundance of these organisms in summer and that of the grazing larvæ as assessed by fly trapping.

Dr. U. Phillip said that we can obtain information about the finer structure of free-living populations by studying both genetical and cytological variability. Genetical variability may be investigated by in breeding insects from the field. It will then be found that every individual is heterozygous for at least one factor, if not for many more. From the occurrence of such factors the structure of the free-living population may be deduced. For the study of structural hybridity the larvæ of the Chironomidæ are very favourable material on account of their large salivary gland chromosomes. By investigating the frequency of various sequences of factors in the chromosomes (inversions) which occur together, it was found that larvæ living together in such a small closed locality as a rainwater butt came from a random mating population of unknown size.

We have so far had only indications of the type of breeding groups that may be found, because ou methods of collecting and evaluating our results statistically are not sufficiently refined.

Prof. J. B. S. Haldane discussed the importance of genetic polymorphism in a wild population. Ht classified polymorphism as (1) manifest, for example as seen in mimetic associations; (2) cytological, ir which the animals appear similar but have differences in chromosomes; (3) cryptic, as where recessivit characters are normally hidden, but may be dis covered to be present by inbreeding.

In the first two cases the population tends to comi to an equilibrium in the proportion of the differen forms, but not in the latter.

$\mathrm{H}_{\Theta}$ pointed out that recoveries of individua Drosophila had been made in wild populations a1 some distance from the laboratories, which showec genès in certain combinations which had first beer made in the laboratories. This indicated their origir by escapes.

An analysis of polymorphism throws light on the breeding system of a population, since a small inbrec group soon becomes homozygous or nearly so. Thi study thus enables us to estimate the rough order 0 magnitude of an interbreeding population.

Mr. E. B. Ford directed attention to the relatior between the size of a population and its variability as seen by him in a locality where the butterfl Melitcea aurinia occurred over a long series of years At first the butterfly was rare and rather uniform in appearance. Then followed a period of rapid increas in numbers accompanied by a great increase in variability. Finally the population settled down ti more or less stability of numbers at a level mucl higher than originally, and simultaneously it becam. much less variable, but not in the same form tha had been dominant at the beginning of the observa tions.

Dr. E. A. Cockayne discussed briefly the problen of melanism and its occurrence in industrial areas $\mathrm{He}$ considered that the melanic forms which becam dominant in certain 'industrial areas' occurred a rarities over the rest of the range of the species. $H_{1}$ also had evidence that there were frequently ver: considerable differences in the proportion of melani forms in some species of moths in localities relativel close to one another, quite independent of any possibl effect of the proximity of manufacturing towns.

Dr. W. Ripper expressed the hope that the methor of correcting a sample for activity so as to leave : more definite population-number effect, as describer by Dr. Williams for his light trap studies, could $b$ extended to other sampling problems, particularl: those of immediate agricultural importanco.

Mr. Classey remarked that the varying proportion of the sexes in different species caught in a light tra] might reduce the value of this as an estimate 0 populations.

Dr. P. A. Buxton, president of the Royal Entomo logical Society, in summing up the discussion emphasized the great scientific and economic import ance of the study of populations and said that nearl: every problem in economic entomology is a problen of numbers. He suggested that it would be mos valuable if someone could produce a critical review 0 the various methods now in use for obtaining estimate of the number of individuals in wild populations. 